\title{
Nocturnal Release of Immunoreactive Growth Hormone-Releasing Hormone and Growth Hormone in Normal Children
}

\author{
PÄIVI TAPANAINEN, HEIKKI RANTALA, JUHANI LEPPÄLUOTO, PENTTI LAUTALA, \\ MARJA-LIISA KÄÄR, AND MIKAEL KNIP \\ Departments of Pediatrics [P.T., H.R., P.L., M.-L.K., M.K.] and Physiology [J.L.] University of Oulu, \\ SF-90220 Oulu, Finland
}

\begin{abstract}
To evaluate the role of growth hormonereleasing hormone $(\mathrm{GHRH})$ in the physiologic release of growth hormone $(\mathrm{GH})$ we studied the nocturnal secretion of immunoreactive GHRH (ir-GHRH) and its relationship to $\mathrm{GH}$ release and various stages of sleep in six prepubertal (three boys) and six pubertal children (two boys) with normal stature. Their ages ranged from 8.1 to $14.9 \mathrm{yr}$ and their bone ages from 6.8 to $14.8 \mathrm{yr}$. Blood was withdrawn continuously between $2200-0600 \mathrm{~h}$ at a constant rate of 5 $\mathrm{mL} / 20 \mathrm{~min}$. The EEG was simultaneously registered. The ir-GHRH and GH data were analyzed by a discrete-pulse detection algorithm (Pulsar). The number of nocturnal irGHRH pulses varied from 0-8 (median 7$)$ and the number of GH peaks from 2-6 (median 3). Pubertal children had significantly more $(p<0.05)$ ir-GHRH pulses and the pulse amplitude was higher $(p<0.05)$ than in the prepubertal children. There were no significant differences in the GH parameters between the two groups. The ir-GHRH peaks were not significantly related to any specific sleep stage. The majority of the GH pulses $(71 \%)$ were associated with slow wave sleep $(p<0.001)$. Two-thirds $(69 \%)$ of the GHRH peaks preceded closely or coincided with GH pulses $(p<0.02)$. Pubertal subjects had more isolated ir-GHRH peaks than prepubertal children $(p<0.05)$. We conclude that the nocturnal secretion of ir-GHRH is pulsatile and, assuming that the peripheral plasma concentrations of ir-GHRH reflect its release from the hypothalamus, GHRH appears to play a physiologic role in the regulation of GH secretion. The partial dissociation between ir-GHRH and GH pulses suggests that other factors are also involved in the regulation of episodic $\mathrm{GH}$ release and/or that some of the circulating ir-GHRH originates from extrahypothalamic sources. Pubertal children have increased ir-GHRH secretion, the importance of which remains to be defined. (Pediatr Res 26: 404-409, 1989)
\end{abstract}

Abbreviations

ir, immunoreactive

GH, growth hormone

GHRH, growth hormone-releasing hormone

Secretory episodes of GH occur within 90-120 min of sleep onset and are associated with slow-wave sleep $(1,2)$. GHRH

Received January 4, 1989; accepted June 19, 1989.

Correspondence and requests for reprints to Päivi Tapanainen, M.D., Department of Pediatrics, University of Oulu, SF-90220 Oulu, Finland.

Supported by the Sigrid Juselius Foundation, Helsinki, Finland to P.T., J.L. M.K. and AIma and K. A. Snellman Foundation, Oulu, Finland to P.T. specifically stimulates GH release in normal men (3-5) and it has been shown that increases in circulating concentrations of ir-GHRH are followed by GH release in some physiologic situations $(6,7)$. However, only a little is known about the role of GHRH in the generation of the nocturnal rhythm of GH secretion. Based on observations obtained by intravenous administration of GHRH in the rat it has been suggested that there is a steady-state GHRH and somatostatin release from the hypothalamus and an additional 3- to 4-h rhythmic surge of each peptide (8). This interplay provides for the integration of the ultradian rhythm of GH secretion, as observed in the peripheral circulation. Plotsky and Vale (9) have demonstrated with direct measurements of ir-GHRH and ir-somatostatin in the hypophysialportal circulation that ir-GHRH is secreted in a pulsatile fashion and that ir-GHRH pulses occur only in the presence of diminished somatostatin release. GHRH infusion studies in man also suggest that $\mathrm{GH}$ secretion is regulated by dynamic interaction between GHRH and somatostatin $(10,11)$. Our study was aimed at evaluating nocturnal variation in the circulating concentrations of ir-GHRH and the possible association between ir-GHRH and GH pulses.

\section{MATERIALS AND METHODS}

Subjects. Twelve healthy children (five $\mathrm{M}$ and seven $\mathrm{F}$ ) participated in this study. Their chronologic ages ranged from 8.1 to $14.9 \mathrm{y}$ and their bone ages from 6.8 to $14.8 \mathrm{y}(12)$. The mean relative ht score was $+0.01 \pm 0.5 \mathrm{SD}$ based on normal growth standards for Finnish children (13). The mean growth velocity before the study was $5.6 \pm 0.8 \mathrm{~cm} / \mathrm{y}$ and $4.9 \pm 1.0$ after the study. Six of the children were prepubertal and the other six pubertal. Their clinical data are given in Table 1. Among the pubertal subjects the pubertal development (14) of the four girls was at stage 3-4 (B 3 or 4, PH 3 or 4) and their fastest growth period was over at the time of the study, whereas the two boys were at stage 2 (G2, PH 2). Written informed consent was obtained from the subjects and their parents. The study was approved by the Ethical Committee of the Medical Faculty, University of Oulu, Finland and carried out according to the provisions of the Declaration of Helsinki and the ethical guidelines of National Institute of Child Health and Human Development (15).

Study design. The children were admitted to the hospital on the study day. They had a light meal $2 \mathrm{~h}$ before the study. A heparinized needle was inserted $30 \mathrm{~min}$ before starting the blood collection. Blood was continuously withdrawn between 2200 $0600 \mathrm{~h}$ through a heparinized catheter at a rate of $5 \mathrm{~mL} / 20 \mathrm{~min}$ with a constant withdrawal pump (CORMED, Medina, NY) according to the Cormed-Kowarski method (16). Chilled polypropylene test tubes containing $500 \mathrm{KIU}$ aprotinin (Apronin, Medica, Finland) and $50 \mu \mathrm{L} 10 \%$ Na 2-EDTA per mL blood, were changed every $20 \mathrm{~min}$ for $8 \mathrm{~h}$. The tubes were kept in ice, 
Table 1. Clinical data on subjects studied; mean $\pm S E M$

\begin{tabular}{lrr} 
& $\begin{array}{c}\text { Prepubertal children } \\
(n=6)\end{array}$ & $\begin{array}{c}\text { Pubertal children } \\
(n=6)\end{array}$ \\
Sex (M/F) & $3 / 3$ & $2 / 4$ \\
Age (yr) & $10.8 \pm 0.8$ & $14.1 \pm 0.3$ \\
Bone age (yr) & $10.1 \pm 0.7$ & $13.2 \pm 0.5$ \\
Ht (cm) & $142.7 \pm 5.1$ & $160.5 \pm 3.8$ \\
Relative ht, SD, score & $-0.12 \pm 0.5$ & $0.13 \pm 0.5$ \\
Preceding growth velocity $(\mathrm{cm} / \mathrm{yr})$ & $5.4 \pm 0.2$ & $5.9 \pm 1.2$ \\
Subsequent growth velocity $(\mathrm{cm} / \mathrm{yr})$ & $6.4 \pm 1.3$ & $3.7 \pm 1.3$ \\
Growth velocity over the total period & $5.8 \pm 0.5$ & $4.6 \pm 0.8$ \\
\hline
\end{tabular}

centrifuged at $1000 \times g$ for $15 \mathrm{~min}$ within $30 \mathrm{~min}$, and the plasma stored at $-70^{\circ} \mathrm{C}$. Sleep was recorded continuously with an eight-channel EEG recorder (Mingograph EEG Universal, Siemens-Elema, Solna, Sweden). Silver-silverchloride cup electrodes were fixed to the scalp with collodion in the $\mathrm{C} 3 \mathrm{P} 3$ and $\mathrm{C} 4 \mathrm{P} 4$ positions along with two reference electrodes at the vertex. Submental electromyogram, eye movements, and heart rate were also recorded on the EEG channels. The EEG recordings were scored as wakefulness, stages 1,2,3,4, and rapid eye movement sleep according to Rechtschaffen and Kales (17). Stages 3 and 4 were considered as slow wave sleep.

Assays. All samples from an individual child were analyzed in the same assay. Plasma ir-GHRH concentrations were measured by RIA as described in detail previously (6). Two $\mathrm{mL}$ of plasma were extracted using Sep-pak C 18 cartridges (Waters Inc., Milford MA). The $\mathrm{pH}$ of the plasma was adjusted to 4.0 with $0.1 \%$ trifluoroacetic acid. The acidified plasma was passed through the cartridge, which was then washed with $10 \mathrm{~mL} 0.5 \%$ triethylamine $(\mathrm{pH}=4.0)$ containing $1 \%$ acetic acid and eluted with $3 \mathrm{~mL} 80 \%$ methanol in $0.5 \%$ triethylamine. The eluate was evaporated and the residual assayed using a rabbit antiserum specific for the mid portion of GHRH and ${ }^{125}$ I-GHRH $1-40$ as tracer (18). Our HPLC analyses have shown that the major ir-GHRH species in the plasma samples eluates as synthetic human GHRH 1-40 (6). The sensitivity of the assay was $1 \mathrm{pg} /$ tube. The mean recovery of synthetic GHRH $1-44$ amide $(25 \mathrm{pg} / \mathrm{mL})$ added to the plasma was $76 \pm 9 \%$ (SD) $(n=6)$ and the results were corrected for recovery. The intra- and interassay coefficients of variation were 11 and $18 \%$, respectively. To verify that the plasma ir-GHRH was stable at $+4^{\circ} \mathrm{C}$ for 20 min 100 pg of synthetic GHRH 1-44 amide was incubated with $5 \mathrm{~mL}$ of fresh human blood containing EDTA and Apronin as in test samples for 0 (centrifuged immediately after mixing) and for $20 \mathrm{~min}$ at $+4^{\circ} \mathrm{C}$. After centrifugation the GHRH-RIA was performed as described before.

The recovery of ir-GHRH added to samples centrifuged immediately $(0)$ was $82.5 \pm 5.1 \%(n=7)$ and that of samples incubated for $20 \mathrm{~min}$ at $+4^{\circ} \mathrm{C} 84.1 \pm 10.3 \%$ ( $n=7$; NS).

Plasma GH concentrations were analyzed in duplicate using a commercial RIA kit obtained from Pharmacia, Uppsala, Sweden. Values below the limit of sensitivity, which was $0.5 \mu \mathrm{g} / \mathrm{L}$, were considered to be $0.5 \mu \mathrm{g} / \mathrm{L}$. The intra- and interassay coefficients of variation were 7 and $12 \%$, respectively. Plasma levels of IGF-I were determined with a commercial kit (Nichols Institute Diagnostics, San Juan Capistrano, CA). The sensitivity of the assay was $0.02 \mathrm{U} / \mathrm{mL}$, the intraassay coefficient of variation was $5.1 \%$ and the interassay variation less than $10 \%$.

Data analysis. Discrete ir-GHRH and GH pulses were identified using Pulsar analysis (19), an objective multipoint, statistically based pulse detection algorithm that removes long-term trends from the series of observations, identifies peaks in the residual series and resolves each peak into overlapping secretory episodes. The SD of the assay is calculated at each point, and the residuals are rescaled in terms of this unit. Pulse criteria were set at a signal to free noise ratio to minimize the occurrence of false positive pulses $<5 \%$. Ir-GHRH and GH release were expressed as integrated values per hour for the time period 2200 $0600 \mathrm{~h}$.
Table 2. Characteristics of variations in nocturnal circulating ir$G H R H$ and $G H$ concentrations in prepubertal and pubertal children; mean \pm SEM if not otherwise indicated

\begin{tabular}{|c|c|c|c|}
\hline & $\begin{array}{l}\text { Prepubertal } \\
\text { children } \\
(n=6)\end{array}$ & $\begin{array}{l}\text { Pubertal } \\
\text { children } \\
(n=6)\end{array}$ & Statistics \\
\hline $\begin{array}{l}\text { No. of ir-GHRH peaks, } \\
\text { median (range) }\end{array}$ & $6(0-8)$ & $8(3-8)$ & $p<0.05$ \\
\hline $\begin{array}{l}\text { No. of ir-GHRH peaks } \\
\text { preceding or coinciding } \\
\text { with GH pulses, me- } \\
\text { dian (range) }\end{array}$ & $5(0-6)$ & $5(3-6)$ & NS \\
\hline Basal ir-GHRH (ng/L) & $6.9 \pm 2.5$ & $11.0 \pm 3.3$ & NS \\
\hline Peak ir-GHRH (ng/L) & $68.0 \pm 15.8$ & $71.4 \pm 19.1$ & NS \\
\hline $\begin{array}{l}\text { Integrated ir-GHRH } \\
(\mathrm{ng} / \mathrm{L})\end{array}$ & $19.7 \pm 4.2$ & $29.5 \pm 8.0$ & NS \\
\hline $\begin{array}{l}\text { Ir-GHRH amplitude } \\
\text { (ng/L) }\end{array}$ & $12.6 \pm 6.8$ & $32.5 \pm 10.9$ & $p<0.05$ \\
\hline $\begin{array}{l}\text { No. of GH peaks, median } \\
\text { (range) }\end{array}$ & $3.5(2-5)$ & $2.5(2-6)$ & NS \\
\hline Basal GH $(\mu \mathrm{g} / \mathrm{L})$ & 0.5 & 0.5 & NS \\
\hline Peak GH $(\mu \mathrm{g} / \mathrm{L})$ & $14.6 \pm 2.5$ & $15.5 \pm 2.4$ & NS \\
\hline Integrated $\mathrm{GH}(\mu \mathrm{g} / \mathrm{L})$ & $4.6 \pm 0.8$ & $5.3 \pm 1.2$ & NS \\
\hline GH amplitude $(\mu \mathrm{g} / \mathrm{L})$ & $7.4 \pm 1.2$ & $10.3 \pm 1.6$ & NS \\
\hline
\end{tabular}

Statistical analysis. The $\chi^{2}$ test was used to assess the relationship between hormone pulses and sleep stages and the relationship between ir-GHRH and GH peaks. The significance of the difference between two groups was estimated by the MannWhitney $U$ test and the correlation between two parameters by Spearman regression analysis. $p$ values $<0.05$ were considerecl significant. The results are expressed as mean $\pm S E M$, if not otherwise indicated.

\section{RESULTS}

Characteristics of the variations in circulating ir-GHRH and GH concentrations in the study subjects are shown in Table 2. The number of nocturnal ir-GHRH pulses varied from $0-8$ (median 7). Pubertal children had significantly more ir-GHRH pulses than prepubertal children $(p<0.05)$. The mean basal irGHRH concentration for all subjects was $9.0 \pm 2.9 \mathrm{ng} / \mathrm{L}$ and the maximal ir-GHRH concentration $69.4 \pm 23.3 \mathrm{ng} / \mathrm{L}$. The mean integrated ir-GHRH concentration for all subjects was $24.6 \pm 6.6 \mathrm{ng} / \mathrm{mL} / \mathrm{h}$. There were no statistically significant differences between the prepubertal and pubertal children in these ir-GHRH parameters. The mean ir-GHRH amplitude was significantly higher in pubertal than in prepubertal children $(p$ $<0.05)$.

The number of $\mathrm{GH}$ pulses during the 8-h sampling period ranged from 2 to 6 (median 3). The mean basal GH concentration was $0.5 \mu \mathrm{g} / \mathrm{L}$ and the mean maximal GH concentration was $15.0 \pm 2.8 \mu \mathrm{g} / \mathrm{L}$. The mean integrated $\mathrm{GH}$ concentration was $4.9 \pm 1.0 \mu \mathrm{g} / \mathrm{L} / \mathrm{h}$ and the mean amplitude of $\mathrm{GH}$ pulses was 8.8 $\pm 1.5 \mu \mathrm{g} / \mathrm{L}$. There were no significant differences in the $\mathrm{GH}$ 
parameters between the prepubertal and pubertal children (Table 2 ). The majority of the $\mathrm{GH}$ pulses $(71 \%)$ was associated with slow wave sleep $(p<0.001)$. Ir-GHRH pulses were not significantly associated with any stage of sleep. The majority of the irGHRH peaks $(69 \%)$ closely preceded (interval $<20 \mathrm{~min}$ ) or coincided with the $\mathrm{GH}$ pulses $(p<0.02)$. On one-third $(31 \%)$ of the occasions, no relationship was seen between the ir-GHRH and $\mathrm{GH}$ peaks. Pubertal children had more isolated ir-GHRH pulses (range $0-3$, median 2.5) than prepubertal children (range $0-2$, median $1.5 ; p<0.05$ ).

A representative pattern of the nocturnal circulating ir-GHRH and GH concentrations in one prepubertal child is shown in Figure 1 and in one pubertal child in Figure 2. No significant correlation was found between the $\mathrm{GH}$ and GHRH parameters. Plasma IGF-I concentrations did not correlate with any of the indicators of ir-GHRH or GH secretion.

\section{DISCUSSION}

A 24-h sampling with standardized intervals has been used to assess spontaneous $\mathrm{GH}$ secretion $(20,21)$. However, there are also studies suggesting that the $\mathrm{GH}$ concentrations during nocturnal sleep can be used as an indicator of GH release instead of the 24-h GH concentrations (22). Inasmuch as sleep is considered to be and is used as a physiologic stimulator of $\mathrm{GH}$ (23), we were interested in studying the possible association between nocturnal ir-GHRH and GH pulses in the peripheral circulation. Instead of discrete samples we used a constant withdrawal pump according to the Cormed-Kowarski method (16). With this method it is possible to get an idea of true nocturnal integrated $\mathrm{GH}$ and irGHRH secretion. Discrete and integrated sampling has been compared in a recent study and no obvious blunting or widening of the peaks using an integrated sampling technique was found (24).

It has been documented previously that children experience both sleep onset difficulty and increased wakefulness after sleep onset resulting in a shorter sleep period and a significantly lower sleep efficiency on their first night in the hospital as compared with subsequent study nights (25). In this study the $\mathrm{GH}$ response may have been stronger if the children had spent some time in the hospital before sampling. However, this was not considered ethically justified because the study subjects were normal, healthy children.

According to our present observations the secretion of irGHRH seems to be pulsatile, because there were considerable variations in ir-GHRH concentrations in the peripheral circulation in normal children during sleep. This finding is in agreement with the study of Plotsky and Vale (9) on rats in vivo. They demonstrated that superimposed upon the tonic release of GHRH and somatostatin from hypothalamus into the hypophyseal portal blood, there are additional rhythmic secretory bursts of GHRH associated with decreased somatostatin secretion.

Administration of GHRH as a bolus produces an acute $\mathrm{GH}$ secretory response in man $(3,5)$. Infusion of GHRH at a constant rate in normal adults produces a persistent effect on $\mathrm{GH}$ secretion that is characterized by enhanced pulsatile secretion and an elevation of baseline GH secretion $(10,26)$. These effects can be observed with infusions as short as a few hours and they persist for as long as $2 \mathrm{wk}$ (27). Accordingly, the infusion studies suggest that $\mathrm{GH}$ pulses are a result of $\mathrm{GHRH}$ secretion and that a finite amount of GH is released by GHRH $(10,11)$. In our study, irGHRH peaks preceded or coincided with GH peaks in a substantial majority $(69 \%)$ of the occasions. This observation indicates that GHRH has an active role in sleep-induced pulsatile GH secretion in children, although we could not find any significant association between the quantitative indicators of the release of the two hormones.

ir-GHRH has been detected in the peripheral circulation by ourselves and others $(6,28-32)$. The source of this circulating irGHRH is, however, uncertain. In addition to the CNS, ir-GHRH has been reported in the gastrointestinal tract $(31,33)$. In rats it
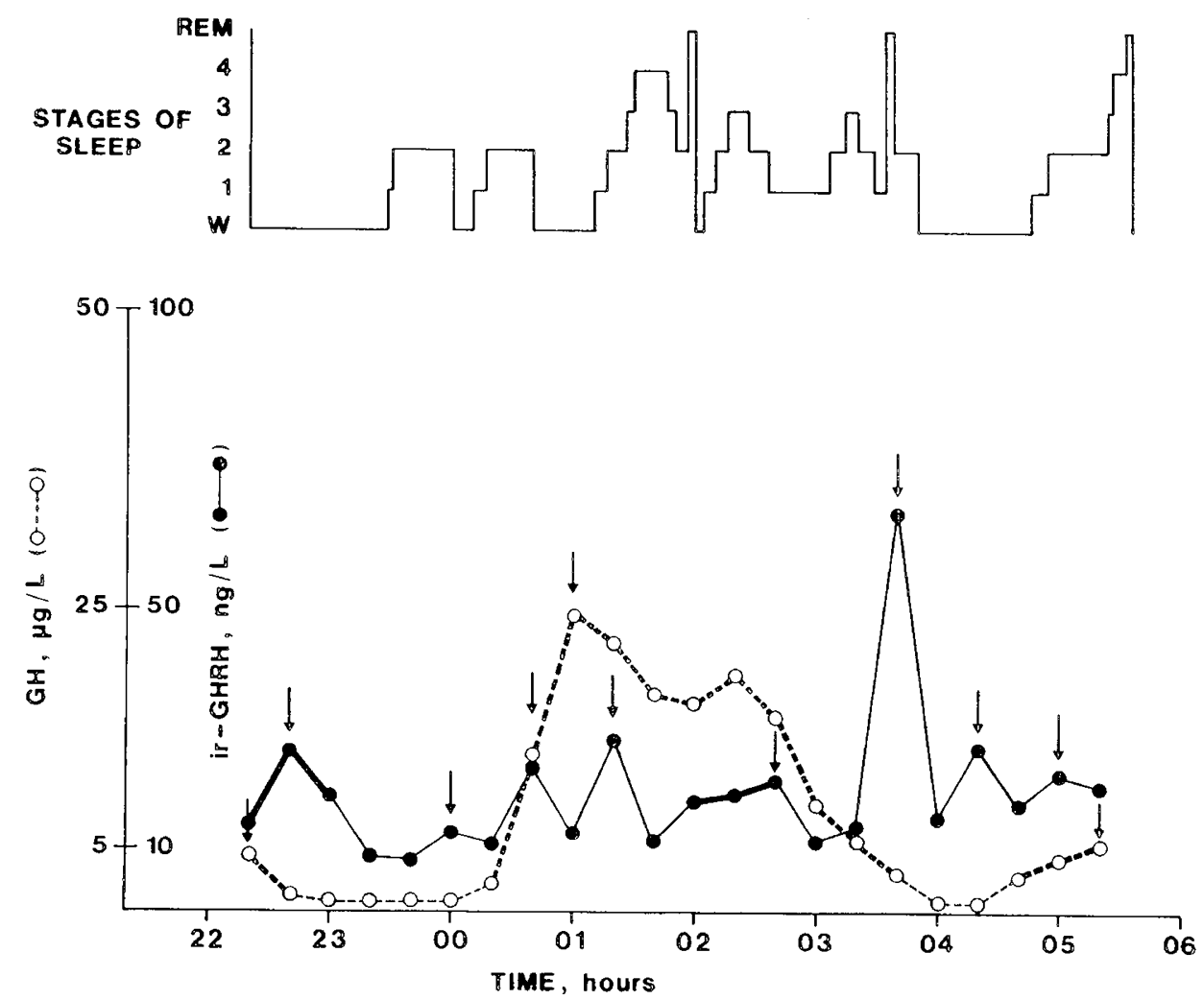

Fig. 1. A representative pattern of nocturnal circulating ir-GHRH and GH concentrations and sleep stages in one prepurbertal child. $\downarrow$ represents the maximal peak values. The duration of each pulse is marked with a strengthened line. 


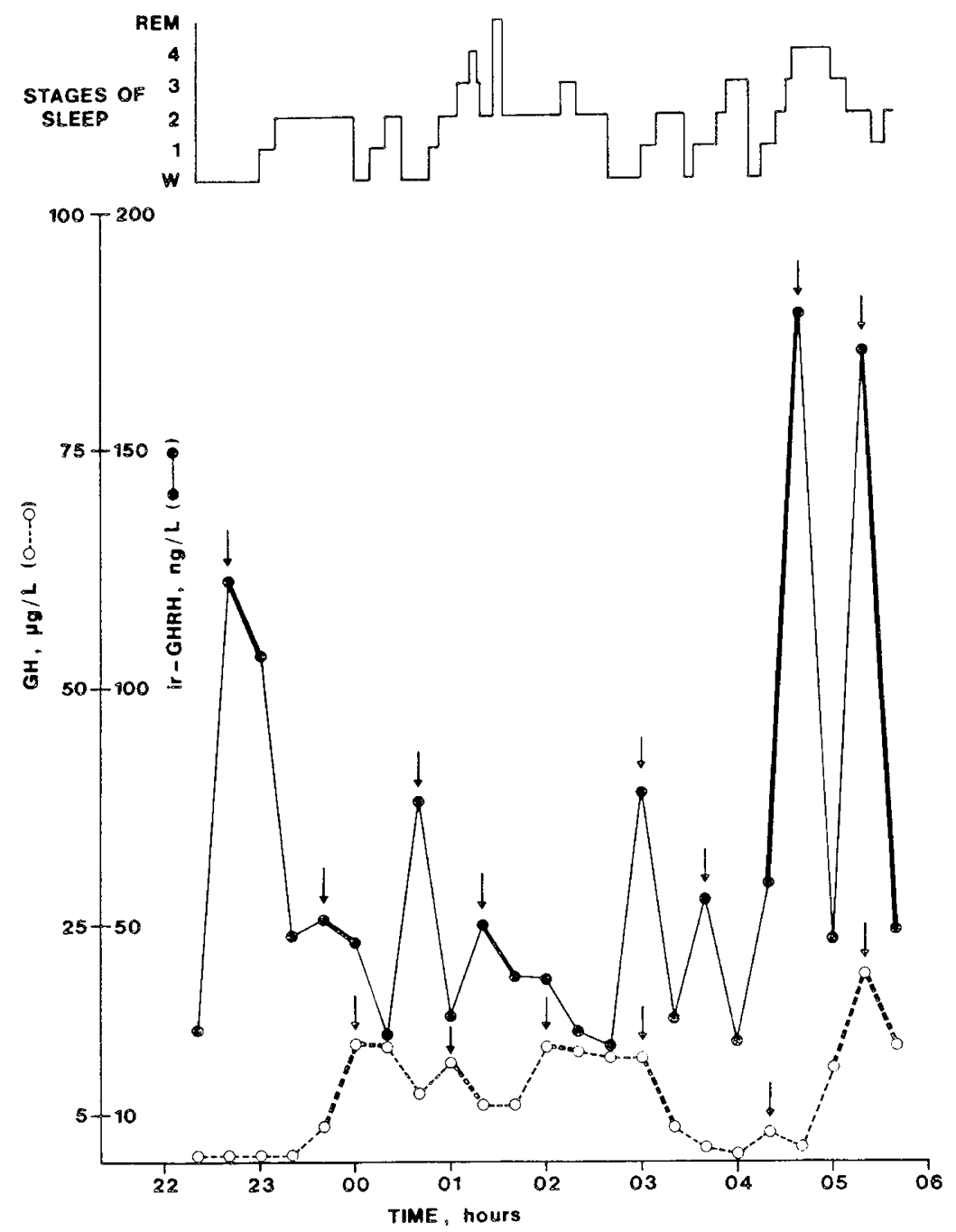

Fig. 2. A representative pattern of nocturnal circulating ir-GHRH and GH concentrations and sleep stages in one pubertal child. $\downarrow$ represents the maximal peak values. The duration of each pulse is marked with a strengthened line.

has been shown that the mechanical ablation of GHRH neurones in the medial basal hypothalamus results in a $70 \%$ reduction of circulating ir-GHRH levels (34), indicating that the majority of the peripheral immunoreactivity could originate from hypothalamic sources. Changes in circulating ir-GHRH concentrations have been claimed to correlate with the secretion of $\mathrm{GH}(35,36)$, suggesting that peripheral plasma ir-GHRH measurements reflect hypothalamic function. Our results support the view that a considerable proportion of human peripheral ir-GHRH is derived from the hypothalamus, because the nocturnal ir-GHRH and GH peaks showed a close temporal relationship in most of the cases.

In our study about one-third of the ir-GHRH peaks were unrelated to $\mathrm{GH}$ peaks, and these isolated $\mathrm{GHRH}$ peaks were found in all but one subject. In addition, we also found a small number of separate $\mathrm{GH}$ peaks unrelated to ir-GHRH pulses. This partial dissociation between ir-GHRH and GH pulses can be interpreted either as an indicator that some of the circulating ir-GHRH originates from extrahypothalamic sources, or as evidence that other factors are involved in the regulation of episodic GH release. Sopwith et al. (37) have also found a dissociation between circulating concentrations of ir-GHRH and GH in normal human subjects. They suggest that an important source of human GHRH is located outside the hypothalamus and that secretion from this source is unrelated to the normal control of pituitary $\mathrm{GH}$ release.

Among other factors regulating pituitary GH secretion, so- matostatin plays an essential role. Endogenous somatostatin decreases the $\mathrm{GH}$ response to GHRH in awake and freely moving rats (38). Vance et al. $(10,11)$ showed partial inhibition of the GH response to continuous GHRH infusion in man, which could either be a direct effect or stimulated by somatostatin. Accordingly, the partial dissociation between the GHRH and GH peaks observed in our study probably reflected both release of extrahypothalamic ir-GHRH and regulatory effects of somatostatin.

Results from previous studies on the effect of puberty on spontaneous GH secretion are conflicting. One group concluded that puberty had no effect on GH secretion (39). Several other investigations, however, have revealed an increased 24-h GH concentration during puberty in both boys and girls $(40,41)$. We did not find any statistically significant differences in GH secretion between prepubertal and pubertal children, although the pubertal subjects tended to have higher integrated and peak $G H$ concentrations as well as higher $\mathrm{GH}$ amplitudes. The lack of significant differences may be due to the small number of subjects studied. In addition, the prepubertal children were relatively old and, although clinically prepubertal, some pubertal hormonal changes may have already been initiated. All but one of the prepubertal children went into puberty during the subsequent year. It has also been documented that the puberty-associated increase in $\mathrm{GH}$ concentration results from an increase in the frequency of $\mathrm{GH}$ pulses during waking hours, and an increase in the amplitude of $\mathrm{GH}$ pulses over $24 \mathrm{~h}$ (23). Accordingly, noctur- 
nal GH secretion may not provide all information on the characteristics of $\mathrm{GH}$ release in puberty.

Our observations demonstrate that the number of nocturnal ir-GHRH pulses and the ir-GHRH amplitude increase in puberty. This is in agreement with the findings of Argente et al. (42) who showed that pubertal children have higher basal plasma ir-GHRH levels than prepubertal children. In our study the increased GHRH secretion in puberty was not reflected, however, in any significant differences in $\mathrm{GH}$ release. It has been shown previously that the $\mathrm{GH}$ response to GHRH infusion is relatively constant during puberty (43). Data on the concentrations of irsomatostatin in the peripheral circulation before and during puberty are scanty. The divergence between increased ir-GHRH release and unchanged $\mathrm{GH}$ secretion in pubertal children can hypothetically be a consequence of enhanced secretion of counteracting somatostatin, an increased release of extrahypothalamic ir-GHRH induced by puberty, or a desensitization of the somatotrophs to GHRH in association with puberty.

Our study shows that the secretion of ir-GHRH is pulsatile, and provided that the peripheral concentrations of ir-GHRH reflect its release from the hypothalamus, GHRH appears to play an active role in nocturnal pulsatile $\mathrm{GH}$ secretion in growing children. The partial dissociation between ir-GHRH and GH pulses indicates that other factors are also involved in the regulation of episodic $\mathrm{GH}$ release and/or that some of the circulating GHRH is derived from sources outside the CNS. Finally, pubertal children are characterized by an increased number of irGHRH pulses and an increased ir-GHRH amplitude.

Acknowledgment. The authors are grateful to Dr. Nicholas Ling, Salk Institute (La Jolla, CA) for the generous supply of GHRH antiserum and peptides.

\section{REFERENCES}

1. Takahashi Y, Kipnis DM, Daughaday WH 1968 Growth hormone secretion during sleep. J Clin Invest 47:2079-2090

2. Honda Y, Takahashi Y, Takahashi S, Azumi K, Irie M, Sakuma T, Tsushima T, Schizume K 1969 Growth hormone secretion during nocturnal sleep in normal subjects. J Clin Endocrinol Metab 29:20-29

3. Thorner MO, Spiess J, Vance ML, Rogol AD, Kaiser DL, Webster JD, Rivier J, Borges JL, Bloom SR, Cronin MJ, Evans WS, MacLeod RM, Vale W 1983 Human pancreatic growth-hormone releasing factor selectively stimulates growth hormone secretion in man. Lancet 1:24-28

4. Vance ML, Borges JL, Kaiser DL, Evans WS, Furlanetto R, Thominet JL, Frohman LA, Rogol AD, MacLeod RM, Bloom S, Rivier J, Vale W, Thorner MO 1984 Human pancreatic growth hormone releasing factor; dose response relationships in normal man. J Clin Endocrinol Metab 58:838-844

5. Rosenthal SM, Schriock EA, Kaplan SL, Guillemin R, Grumbach MM 1983 Synthetic human pancreas growth hormone-releasing factor (hpGRF 1-44NH2) stimulates growth hormone secretion in normal men. J Clin Endocrinol Metab 57:677-679

6. Leppäluoto J, Tapanainen P, Knip M 1987 Heat exposure elevates plasma immunoreactive growth hormone-releasing hormone levels in man. J Clin Endocrinol Metab 65:1035-1038

7. Kashio YK, Chihara K, Kira T, Okimura Y, Sato M, Kadowaki S, Fujita $\Upsilon$ 1987 Effect of oral glucose administration on plasma growth hormonereleasing hormone (GHRH)-like immunoreactivity levels in normal subjects and patients with idiopathic GH deficiency: evidence that GHRH is released not only from the hypothalamus but also from extrahypothalamic tissue. J Clin Endocrinol Metab 64:92-97

8. Tannenbaum GS, Ling N 1984 The interrelationship of growth hormone (GH)-releasing factor and somatostatin in generation of the ultradian rhythm of GH secretion. Endocrinology 115:1952-1957

9. Plotsky PM, Vale W 1985 Patterns of growth hormone-releasing factor and somatostatin secretion into the hypophysial-portal circulation of the rat. Science 230:461-463

10. Vance ML, Kaiser DL, Evans WS, Thorner MO, Furlanetto R, Rivier J, Vale W, Perisutti G, Frohman LA 1985 Evidence for a limited growth hormone (GH)-releasing hormone (GHRH)-releasable quantity of GH: effects of 6hour infusions of GHRH on $\mathrm{GH}$ secretion in normal man. J Clin Endocrinol Metab 60:370-375

11. Vance ML, Kaiser DL, Evans WS, Furlanetto R, Vale W, Rivier J, Thorner MO 1985 Pulsatile growth hormone secretion in normal man during a continuous 24-hour infusion of human growth hormone releasing factor (140). J Clin Invest 75:1584-1590
12. Greulich WW, Pyle SI 1959 Radiographic Atlas of Skeletal Development of the Hand and the Wrist, Ed 2. Stanford University Press, Stanford

13. Sorva R, Perheentupa J, Tolppanen EM 1984 A novel format for a growth chart. Acta Paediatr Scand 73:527-529

14. Tanner JM, Whitehouse RH 1976 Clinical longitudinal standards for height, weight, height velocity and stages of puberty. Arch Dis Child 51:170-179

15. National Institute of Health Clinical Center 1979 Research involving children. Policy and communications bulletin, vol 1. NIH, Bethesda, MD, pp 1-5

16. Kowarski A, Thompson RG, Migeon CJ, Blizzard RM 1971 Determination of integrated plasma concentrations and true secretion rate of human growth hormone. J Clin Endocrinol Metab 32:356-360

17. Rechtschaffen A, Kales A 1968 A Manual of Standardized Terminology, Techniques and Scoring System for Sleep Stages of Human Subjects. Brain information Service/Brain Research Institute, University of California, Los Angeles, pp 1-57

18. Baird A, Wehrenberg WB, Böhlen P, Ling N 1985 Immunoreactive and biologically active growth hormone-releasing factor in the rat placenta. Endocrinology 117:1598-1601

19. Merriam GR, Wachter KW 1982 Algorithms for study of episodic hormone secretion. Am J Physiol 243:E310-E318

20. Spiliotis BE, August GP, Hung W, Sonis W, Mendelsohn W, Bercu BB 1984 Growth hormone neurosecretory dysfunction. A treatable cause of short stature. JAMA 251:2223-2230

21. Albertsson-Wikland K, Rosberg S, Westphal O 1984 24-hour secretory pattern of growth hormone in tall and short children. Pediatr Res 18:102

22. Costin G, Kaufman FR 1987 Growth hormone secretory patterns in children with short stature. J Pediatr 110:362-368

23. Siegel SF, Becker DJ, Lee PA, Gutai JP, Foley TP, Drash AL 1984 Comparison of physiologic and pharmacologic assessment of growth hormone secretion. Am J Dis Child 138:540-543

24. Albertsson-Wikland K, Rosberg S 1988 Analyses of 24-hour growth hormone profiles in children: relation to growth. J Clin Endocrinol Metab 67:493 500

25. Coble PA, Kupfer DJ, Taska LS, Kane J 1984 EEG sleep of normal healthy children. Part I: findings using standard measurement methods. Sleep 7:289303

26. Webb CM, Vance ML, Thorner MO, Perisutti G, Thominet J, Rivier J, Vale W, Frohman LA 1984 Plasma growth hormone responses to constant infusions of human pancreatic growth hormone releasing factor: intermitten secretion or response attenuation. J Clin Invest 74:96-103

27. Vance ML, Kaiser DL, Rivier J, Vale W, Thorner MO 1986 Dual effects of growth hormone (GH)-releasing hormone infusion in normal men: somatotropin desensitization and increase in releasable GH. J Clin Endocrino Metab 62:591-594

28. Donnadieu M, Evain-Brion D, Tonon MC, Vaudry H, Job JC 1985 Variations of plasma growth hormones (GH-) releasing factor levels during $\mathrm{GH}$ stimulation tests in children. J Clin Endocrinol Metab 60:1132-1134

29. Tapanainen P, Knip M, Lautala P, Leppäluoto J 1988 Variable plasma growth hormone $(\mathrm{GH})$-releasing hormone and $\mathrm{GH}$ response to clonidine, L-dopa and insulin in normal men. $J$ Clin Endocrinol Metab 67:845-849

30. Thorner MO, Frohman LA, Leong DA, Thominet J, Downs T, Hellman P, Chitwood J, Vaughan JM, Vale W 1984 Extrahypothalamic growth hor mone-releasing factor (GRF) secretion is a rare cause of acromegaly: plasma GRF levels in 177 acromegalic patients. J Clin Endocrinol Metab 59:846849

31. Shibasaki T, Kiyosawa Y, Masuda A, Nakahara M, Imaki T, Wakabayashi I, Demura H, Shizume K, Ling N 1984 Distribution of growth hormonereleasing hormone-like immunoreactivity in human tissue extracts. $\mathrm{J}$ Clin Endocrinol Metab 59:263-268

32. Chihara K, Kashio Y, Kita T, Okimura Y, Kaji H, Abe H, Fujita T 1986 L Dopa stimulates release of hypothalamic growth hormone releasing hormone in humans. J Clin Endocrinol Metab 62:466-473

33. Christofides ND, Stephanou A, Suzuki H, Yiangou Y, Bloom SR 1984 Distribution of immunoreactive growth hormone releasing hormone in the human brain and intestine and its production by tumours. J Clin Endocrino Metab 59:747-751

34. Lina L, Carolto MC, Dall'Ara A, Cocchi D 1988 Significance of circulating immunoreactive growth hormone releasing hormone: CNS vs peripheral source. 70th Annual Meeting of the Endocrine Society, New Orleans, LA June 8-11, abstr 261

35. Saito H, Saito S, Yamayaki R, Hosoi E 1984 Clinical value of radioimmunoassay of plasma growth-hormone-releasing factor. Lancet 2:401-402

36. Smith PJ, Pringle PJ, Rafferty B, Brook CGD 1985 The relationship between endogenous immunoreactive GRH and GH secretion. J Endocrinol (supp 104):86

37. Sopwith A, Penny ES, Lytras N, Besser GM, Rees LH 1987 Dissociation between circulating concentrations of immunoreactive growth hormone releasing factor and growth hormone in normal human subjects. Clin Sc 72:181-185

38. Wehrenberg WB, Ling N, Böhlen P, Esch F, Brazeau P, Guillemin R 1982 Physiological roles of somatocrinin and somatostatin in the regulation of growth hormone secretion. Biochem Biophys Res Commun 109:562-567

39. Thompson RG, Rodriquez A, Kowarski A, Blizzard 1972 Integrated concen tration of growth hormone correlated with plasma testosterone and bone age in preadolescent and adolescent males. J Clin Endocrinol Metab 35:334337 
40. Minuto F, Barreca A, Ferrini S, Mazzochi G, Del Monte P, Giordano G 1982 Growth hormone secretion in pubertal and adult subjects. Acta Endocrinol 99:161-165

41. Zadik Z, Chalew SA, McCarter J Jr, Mesitas M, Kowarski AA 1985 The influence of age on the $24 \mathrm{hr}$ integrated concentration of growth hormone. $\mathrm{J}$ Clin Endocrinol Metab 60:513-516

42. Argente J, Evain-Brion D, Munoz-Villa A, Garnier P, Hernandez M, Donna- dieu M 1986 Relationship of plasma growth hormone releasing hormone levels to pubertal changes. J Clin Endocrinol Metab 63:680-682

43. Gelato MC, Malozowski S, Caruso-Nicoletti M, Levine Ross J, Pecovitz OH, Rose S, Loriaux DL, Cassora F, Merriam GR 1986 Growth hormone (GH) responses to $\mathrm{GH}$-releasing hormone during pubertal development in normal boys and girls: comparison to idiopathic short stature and GH deficiency. J Clin Endocrinol Metab 63:174-179

\section{Announcements}

\section{Abstract Deadline}

The American Pediatric Society and The Society for Pediatric Research announce the abstract deadline for the 1990 Annual Meeting (May 7-11, 1990, Anaheim Hilton \& Convention Center, Anaheim, CA) has been set as January 4, 1990.

For further information contact: 2650 Yale Blvd., S.E., Suite 104, Albuquerque, NM 87106 (505) 764-9099.

\section{Joint PhD-Fellowship Training Program}

The University of Chicago Department of Pediatrics announces its unique, new Pediatric Science Training/ PhD Program. Trainees wishing to pursue an academic career may simultaneously pursue subspecialty training and a graduate school program leading to the $\mathrm{PhD}$ degree in this 5-year program. Training is available in most pediatric subspecialties, and research opportunities are available in diverse fields, including the social and behavioral sciences as well as the biological sciences. Applications are being accepted for 1990 and 1991. This program is funded by the National Institutes of Child Health and Human Development. Address inquiries to Robert L. Rosenfield, MD, Program Director, Pediatric Science Training/PhD Program, Wyler Children's Hospital, 5841 South Maryland, Chicago, IL 60637.

\section{7th Annual Seminar in Pediatric Nephrology}

The 17th Annual Seminar in Pediatric Nephrology, "Current Concepts in Diagnosis and Management," will be held at the Diplomat Hotel and Country Club, Hollywood, FL, February 5-10, 1990. For more information contact Pearl Seidler, Division Coordinator, Department of Pediatrics, Division of Pediatric Nephrology, University of Miami School of Medicine, P.O. Box 016960, Miami, FL 33101, (305) 549-6726.

\section{Update on Diabetes in Childhood}

The International Study Group on Diabetes in Children and Adolescents (ISGD) announces a course on "Update on Diabetes in Childhood," March 17-24, 1990, in Malga, Ciapela, Marmolada, Italy. The course is addressed to pediatricians, practitioners, and endocrinologists dealing with children and adolescents. Directors of the course of Dr. L. Pinelli, University of Verona, Italy, and Prof. Z. Laron, Tel Aviv University, Israel. The scientific program will be held in the mornings and evenings, and during the day winter sports can be enjoyed in the Alps. For further information contact Dr. L. Pinelli, Servizio di Diabetologia Pediatrica, Policlinico, I-37134, Verona, Italy; Telephone 0039-45-933667; FAX 0039-45-508222.

\section{Hyperlipidemia in Childhood and the Development of Atherosclerosis}

A conference on Hyperlipidemia in Childhood and the Development of Atherosclerosis will be held May 2-4, 1990, at the Hyatt Regency, Bethesda, MD. This conference will examine the role of hyperlipidemia and dyslipidemia in childhood in relation to the development of atherosclerosis. The program will focus initially on morphologic development of the atherosclerotic plaque, pathologic findings in pediatric autopsy series, biochemical correlates, and cellular models of atherosclerosis in the young. Distribution of plasma cholesterol and lipoprotein levels in children will be reviewed, including genetic, dietary, developmental, lifestyle, and pharmacologic influences on serum levels. Tracking of lipid levels over time will be reviewed, as well as international comparisons of lipids in pediatric populations. Cholesterol screening of children will be presented both from high-risk and population-based viewpoints. Pediatric office-based, school-based, and community-wide cholesterol screening activities and interventions will be described. Dietary and pharmacologic therapy of lipid disorders in children will be presented. Abstract deadline is December 11, 1989. The abstract, including title, author(s), and affiliation must be typed single space within a $5 \times 4-3 / 8$ inch rectangle, and sent to Dr. Christine L. Williams, Preventive Cardiology Center, New York Medical College, Valhalla, New York 10595. For further information, contact Conference Department, The New York Academy of Sciences, 2 East 63rd Street, New York, NY 10021, (212) 838-0230. 